\title{
Ege Üniversitesi Hastanesinde erkek genital sistem kanserlerinin epidemiyolojik ve genel sağ kalım özellikleri
}

\section{Epidemiological and overall survival characteristics of male genital system cancers in Ege University Hospital database}

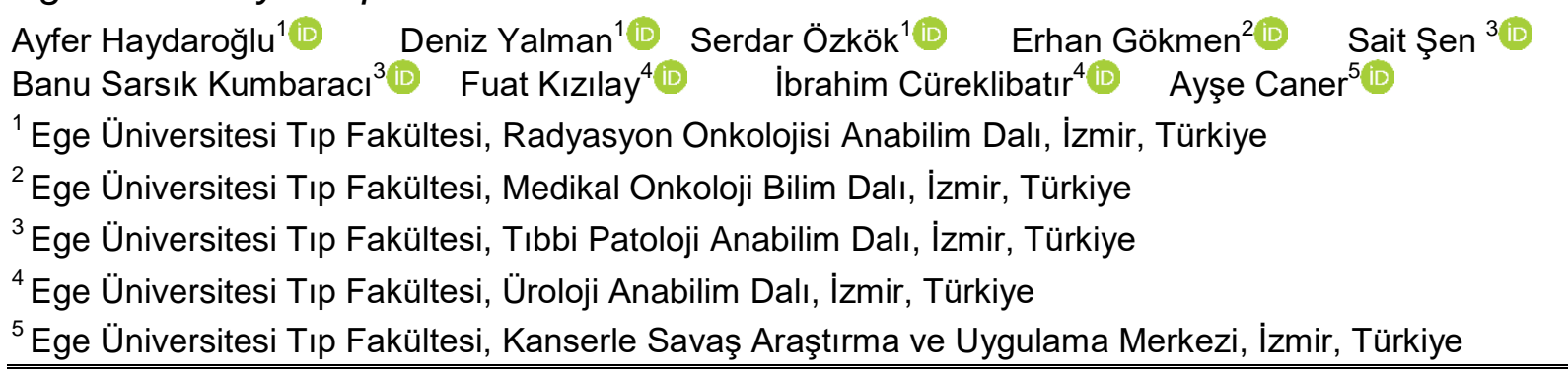

Öz

Amaç: Ege Üniversitesi Hastanesi'nde (EÜH) Erkek Genital Sistem Kanseri (EGSK) tanısı ile tedavileri yapılan 5.634 kayıtlı olgunun epidemiyolojik ve genel sağ kalım (GSK) özelliklerini istatistiksel açıdan değerlendirmektir.

Gereç ve Yöntem: Sınıflandırmalarda ve sağ kalım analizlerinde "Surveillance, Epidemiology, and End Results" (SEER) verileri göz önüne alınmıştır. CANREG-4 programı ile kaydedilen veriler SPSS programına aktarılmıştır. İstatistik analizde Ki-kare yöntemi ve doğrusal modellemeler yapılmış ve $\mathrm{p}<0,05$ anlamlı kabul edilmiştir.

Bulgular: EGSK, EÜH kanser olgularının \%5,3'ni, erkek kanserlerinin \%10,1'ni oluşturmaktadır. EGSK'lerinin \%84,7'si prostat, \%15,3'ü ise testis yerleşimlidir. EGSK'lerinin yaş gruplarına göre dağılımında prostat kanserleri en sık 60-69 yaş grubunda, testis tümörleri ise 30-39 yaş grubunda yer almaktadır. Evrelendirme yapılabilen prostat kanserleri \%60,9 lokalize, \%20,2 lokal ileri, \%16,8 metastatik dönemde tanı almışlardır. Prostat kanserinde yıllara göre doğrusal bir artış vardır $(p<0,0001)$, testis tümöründe ise artış saptanmamıştır. Prostat kanserlerimizde medyan sağ kalım 120 ay, 5 ve 10 yıllık genel sağ kalım (GSK) oranları \%74,2 ve \%55,2'dir. Evrelere göre 5 ve 10 yıllık sağ kalım oranları sırasıyla; lokalize evrede $\% 86,3$ ve $\% 70$, lokal ileri evrede $\% 78,1$ ve $\% 62,7$, metastatik dönemde $\% 21,7$ ve $\% 14$ 'tür. Testis tümörlerinde olguların \%45,4'ü seminom, \%54,6'sı nonseminomdur. Testis tümörlerinde 5 ve 10 yıllık sağ kalımlar sırasıyla \%86,6 ve \%82,9'dir. Histopatolojiye göre 5 ve 10 yıllık GSK sırasıyla; seminomlarda \%95,7 ve \%94,2, nonseminomlarda ise $\% 80.6$ ve $\% 75,2$ 'dir $(p<0,001)$.

Sonuç: EÜH'de EGSK'lerinin \%84,7'si prostat, \%15,3'ü testis tümörüdür. Yıllar içinde prostat kanserinde doğrusal artış saptanmış, 5 ve 10 yıllık GSK oranları prostat kanseri için sırasıyla $\% 74,2$ ve $\% 55,2$, testis tümörlerinde \%86,6 ve \%82,9 bulunmuştur. Seminomlarda 10 yıllık sağ kalım \%94,2 iken non-seminomlarda \%75,2'ye düşmektedir.

Anahtar Sözcükler: Erkek genital kanser, prostat kanseri, testis tümörü, epidemiyoloji, insidans, mortalite.

\begin{abstract}
Aim: The aim of this study is to evaluate the epidemiological and survival characteristics of 5634 patients with Male Genital System Cancer (MGSC) who were treated at Ege University Hospital (EUH).
\end{abstract}

\footnotetext{
Yazışma Adresi: Ayfer Haydaroğlu

Ege Üniversitesi Tıp Fakültesi, Radyasyon Onkolojis

Anabilim Dalı, İzmir, Türkiye

E-mail: haydaroglua@gmail.com
} 
Materials and Methods: Surveillance, Epidemiology, and End Results (SEER) data were considered for classification and survival analysis. The data were recorded using the CANREG-4 program and transferred to SPSS program for statistical analysis. Chi-square test and linear model was used for statistical analysis, and $p<0.05$ value was considered significant.

Results: MGSC accounts for $5.3 \%$ of all EUH cancer patients and $10.1 \%$ of all male cancers. $84.7 \%$ were located in the prostate, and $15.3 \%$ in the testis. According to the age groups prostate cancer was more frequent in males aged 60-69 years, whereas testicular cancer was more frequent in males aged 30-39 years. Among the prostate cancer patients $60.9 \%$ had localized, $20.2 \%$ had locally advanced, and $16.8 \%$ had metastatic disease. There is a linear increase in prostate cancer according to years $(p<0.0001)$, whereas no significant increase was detected for testicular cancer. Median survival for prostate cancer was 120 months. Five and 10-year overall survival (OS) rates were $74.2 \%$ and $55.2 \%$ respectively. 5- and 10 year OS rates according to stage were $86.3 \%$ and $70 \%, 78.1 \%$ and $62.7 \%, 21.7 \%$ and $14 \%$ for localized, locally advanced and metastatic disease respectively. For testicular tumors $45.4 \%$ were seminoma and $54.6 \%$ were non-seminoma. Five and 10-year OS rates for testicular tumors were $86.6 \%$ and $82.9 \%$ respectively. The same rates for seminomas were $95.7 \%$ and $94.2 \%$, and for non-seminomas were $80.6 \%$ and $75.2 \%$ respectively $(p<0,001)$.

Conclusions: Among MGSC patients who were treated at EUH $84.7 \%$ were prostate and $15.3 \%$ were testicular cancers. A linear increase according to years was detected for prostate cancer. 5- and 10-year overall survival (OS) rates for prostate, and testicular cancer were $74.2 \%$ and $55.2 \%$, and $86.6 \%$ and $82.9 \%$ respectively. Ten-year OS rate for seminomas was $94.2 \%$ whereas it decreased to $94.2 \%$ for nonseminomas.

Keywords: Male genital cancer, prostate cancer, testicular tumor, epidemiology, incidence, mortality.

\section{Giriş}

Erkeklerde en sık görülen kanserler akciğer ve prostat kanserleridir. Dünya genelinde kanser sıklığına baktığımızda erkeklerde Kuzey ve Güney Amerika'daki tüm ülkeler, Avustralya, Avrupa'nın bir çok ülkesi ve Afrika'nın bir bölümü dahil olmak üzere 87 ülkede prostat kanseri en sık görülen kanserdir. Akciğer kanseri ise Rusya, Çin, Doğu Avrupa ve Kuzey Afrika'nın bir bölümünde ve Türkiye dahil 38 ülkede erkeklerde en sık görülen kanserdir (1). GLOBOCAN 2018 verilerine göre tüm dünyada erkeklerde kanser insidansında sıklık açısından sıralamada akciğer kanseri \%14,5 ile birinci sırada olup prostat kanseri \%13,5 pay ile akciğer kanserini yakından izlemektedir. Mortalite açısından ise prostat kanseri akciğer, karaciğer, mide, kolorektal kanserlerin arkasından beşinci sırada yer almaktadır (2). Amerika Birleşik Devletleri'nde ise insidansda prostat kanseri birinci sıradayken mortalitede akciğer kanserinin hemen ardından ikinci sıradadır (3). Avrupa çalışmasında Ferlay ve ark. prostat kanserini insidansta birinci sırada, mortalitede ise akciğer ve kolorektal kanser arkasından üçüncü sırada bulmuşlardır (4). Türkiye Birleşik Veri Tabanında ise erkeklerde genital sistem kanserleri solunum ve sindirim sistemi kanserlerinden sonra üçüncü sırada gelmektedir (5).

Organ bazında ele alındığında prostat kanseri akciğer kanserinden sonra ikinci sırada sık görülmektedir.
$\mathrm{Bu}$ makalede Ege Üniversitesi Hastanesi'nde (EÜH) 1992-2017 yılları arasında Erkek Genital Sistem Kanseri (EGSK) tanısı ile tedavileri yapılan 5634 kayıtlı olgunun epidemiyolojik ve genel sağ kalım (GSK) özellikleri istatistiksel açıdan değerlendirilmiş, sonuçlarımız literatürle karşılaştıııımıştır. Bu çalışma 23. Ulusal Kanser Kongresinde sunulmuş olup ilgili anabilim dallarının müsaadesiyle etik onay alınarak yayınlanmaktadır.

\section{Gereç ve Yöntem}

Ege Üniversitesi Kanserle Savaş Araştırma ve Uygulama Merkezi (EÜKAM)'nin özel eğitimli ve sertifikalı kanser kayıt elemanları tarafından 1992-2017 arasında, 25 yıl içinde EÜH'de EGSK tanılı 5634 kanser kaydı yapılmıştır. Sınıflandırmalarda ve sağ kalım analizlerinde SEER verileri göz önüne alınmıştır. CANREG-4 programı ile kaydedilen veriler SPSS programına aktarılmıştır. İstatistik analizde ki-kare yöntemi ve doğrusal modellemeler yapılmış ve $p<0,05$ anlamlı kabul edilmiştir.

\section{Bulgular}

EÜH'de EÜKAM tarafından, 1992-2017 arası 25 yıl içinde 117.139 kanser verisi toplanmıştır. Melanom dışı cilt kanserleri çıkarılırsa toplam olgu sayısı 107.238 'dir. Melanom dışı cilt kanserleri hariç kanser verilerimizin \%5,3'ni, erkek olguların ise \%10,1'ni EGSK oluşturmaktadır (Tablo-1). 
Tablo-1. Kayıtlı kanser olgularının sistemler ve cinsiyetlere dağılımı.

\begin{tabular}{lcccccc}
\hline \multirow{2}{*}{ Sistemlere Göre Dağılım } & \multicolumn{2}{c}{ Erkek } & \multicolumn{2}{c}{ Kadın } & \multicolumn{2}{c}{ Toplam } \\
\cline { 2 - 6 } Gastrointestinal sistem & $\mathbf{n}$ & $\%$ & $\mathbf{n}$ & $\%$ & $\mathbf{n}$ & $\%$ \\
Baş ve boyun & 11.923 & 21,3 & 7.619 & 14,9 & 19.542 & 18,2 \\
Solunum sistemi & 7.225 & 12,9 & 8.176 & 15,9 & 15.401 & 14,4 \\
Meme & 12.507 & 22,4 & 1.745 & 3,4 & 14.252 & 13,3 \\
Kadın genital & 170 & 0,3 & 12.909 & 25,2 & 13.079 & 12,2 \\
Kan-kemik iliği & 0 & 0,0 & 8.332 & 16,2 & 8.332 & 7,8 \\
Üriner sistem & 3.739 & 6,7 & 2.924 & 5,7 & 6.663 & 6,2 \\
Merkezi sinir sistemi & 4.744 & 8,5 & 1.288 & 2,5 & 6.032 & 5,6 \\
Erkek genital & 2.949 & 5,3 & 2.928 & 5,7 & 5.877 & 5,5 \\
Lenf sistemi & 5.634 & 10,1 & 0 & 0,0 & 5.634 & 5,3 \\
Primeri bilinmeyen & 2.298 & 4,1 & 1.623 & 3,2 & 3.921 & 3,7 \\
Nadir tümörler & 2.053 & 3,7 & 1.397 & 2,7 & 3.450 & 3,2 \\
Bağ dokusu & 949 & 1,7 & 945 & 1,8 & 1.894 & 1,8 \\
Kemik-eklem & 942 & 1,7 & 837 & 1,6 & 1.779 & 1,7 \\
Toplam & 813 & 1,5 & 569 & 1,1 & 1.382 & 1,3 \\
Ki-kare: 37746,$311 ; \mathrm{p}<0,0001$ & 55.946 & 100,0 & 51.292 & 100,0 & 107.238 & 100,0 \\
\hline
\end{tabular}

EGSK'nde $4759(\% 84,5)$ prostat kanseri, 861 $(\% 15,39)$ testis tümörü ve $14(\% 0,2)$ diğer erkek genital organ kanseri bulunmaktadır. Prostat ve testis dışında altı penis, beş skrotum ve bir epididim kanseri vardır (Tablo-2, Şekil-1).

Tablo-2. Erkek genital sistem kanserlerinde yerleşim dağııımı.

\begin{tabular}{|c|c|c|c|}
\hline \multicolumn{2}{|c|}{ Erkek Genital Sistemi } & \multirow{2}{*}{$\frac{\mathbf{n}}{4.759}$} & \multirow{2}{*}{$\frac{\%}{84,5}$} \\
\hline \multirow{8}{*}{ 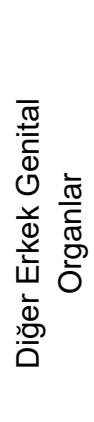 } & Prostat & & \\
\hline & Testis & 861 & 15,3 \\
\hline & Penis & 6 & \\
\hline & Epididim & 1 & \\
\hline & Skrotum, NOS & 5 & \\
\hline & $\begin{array}{l}\text { Erkek genital } \\
\text { organları, NOS }\end{array}$ & 2 & \\
\hline & Toplam & 14 & 0,2 \\
\hline & Toplam & 5.634 & 100,0 \\
\hline
\end{tabular}

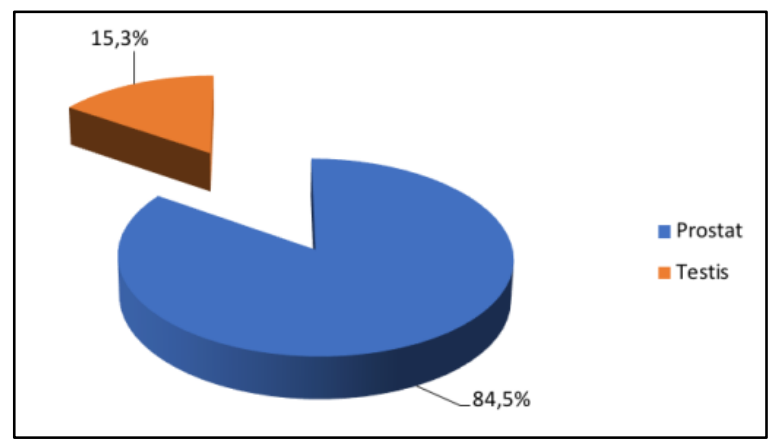

Şekil-1. Erkek genital sistem kanserlerinde yerleşim dağııımı.

EGSK'nin yaş gruplarına göre dağılımında prostat kanserleri en sık 60-69 yaş grubunda, testis tümörleri ise 30-39 yaş grubunda yer almaktadır. Prostat kanserlerinin ileri yaşlarda, testis tümörlerinin ise daha genç yaşlarda rastlanması istatistik açıdan anlamlıdır (Kikare:4527,265 $\mathrm{p}<0,0001$ ) (Şekil-2). 


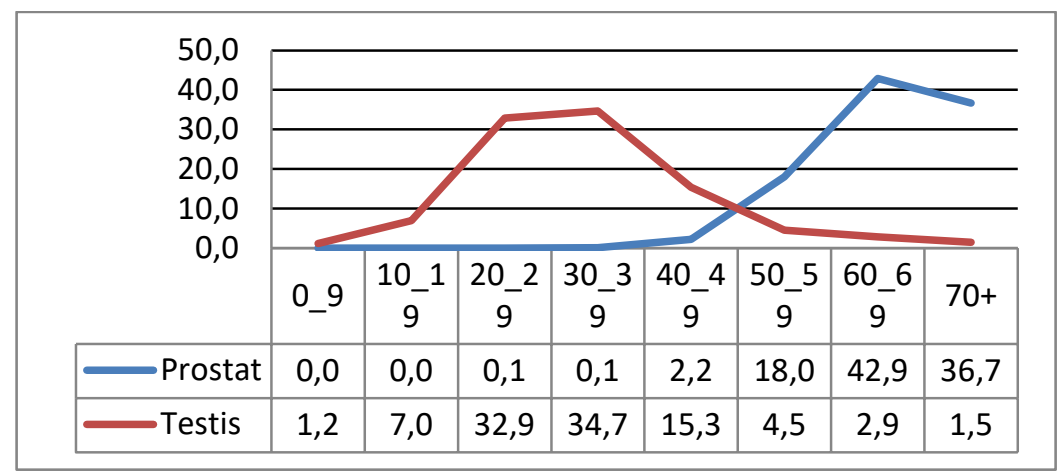

Şekil-2. Erkek genital sistemi kanserlerinin yaş gruplarına göre dağılımları.

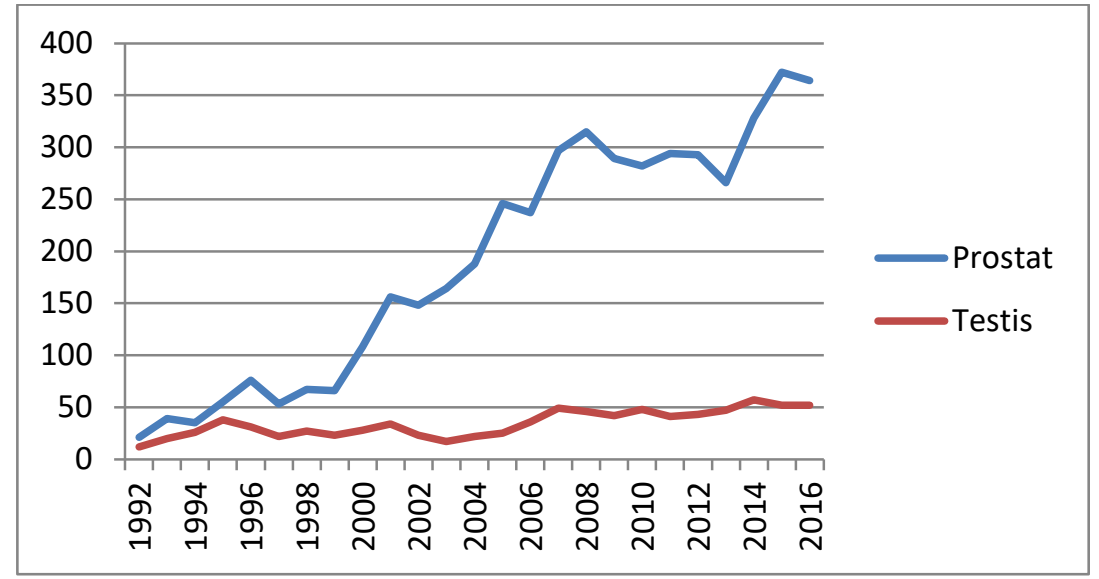

Şekil-3. Erkek genital sistem kanserlerinde yıllara göre artış eğilimi.

Evrelendirme yapılan prostat kanserlerinin $\% 60,9$ 'u lokalize, \%20,2'si lokal ileri, \%16,8'i metastatik dönemde tanı almışlardır (Tablo-4).

Tablo-4. Prostat kanserlerinde tanıda evrelere göre dağılım.

\begin{tabular}{lcc}
\hline Evre & $\mathbf{n}$ & $\%$ \\
\hline Insitu & 64 & 2,2 \\
Lokalize Tm. & 1.807 & 60,9 \\
Lokal ileri & 600 & 20,2 \\
Metastatik & 498 & 16,8 \\
Toplam & 2.969 & 100,0 \\
\hline
\end{tabular}

Daha önceki döneme ait prostat kanseri analizlerinde lokal ileri ve metastatik dönemde tanı daha sık iken 25. yıl değerlendirmemizde lokal evrede tanı artmış ve \%61'e ulaşmıştır. Giderek daha erken evrelerde prostat kanseri tanısı alma anlamlıdır ( $p<0,0001)$. EÜH kanser verilerinde prostat kanseri görülme sıklığında yıllara göre doğrusal bir artış olduğu $(p<0,0001)$, testis tümörlerinde ise olmadığı saptanmıştır (Şekil-3).

Prostat kanserinde medyan sağ kalım 120 ay olup tüm prostat kanserlerinde beş ve 10 yıllık GSK \%74,2 ve \%55,2'dir. Evrelere göre beş ve 10 yıllık sağ kalım oranları sırasıyla; lokalize evrede $\% 86,3$ ve $\% 70$, lokal ileri evrede $\% 78,1$ ve $\% 62,7$ ve metastatik dönemde ise $\% 21,7$ ve \%14'tür (Tablo-5, Şekil-4).

Tablo-5. Prostat kanseri sağ kalımının evrelere göre dağılımı.

\begin{tabular}{lccccc}
\hline Evre & $\mathbf{n}$ & $\begin{array}{c}\text { Ölüm } \\
\mathbf{n}\end{array}$ & $\begin{array}{c}\text { Yaşayan } \\
\mathbf{\%}\end{array}$ & $\mathbf{5}$ yıl & $\mathbf{1 0}$ yıl \\
\hline İn situ & 64 & 19 & 70,3 & $\mathbf{7 5 , \mathbf { 1 }}$ & $\mathbf{6 4 , 0}$ \\
Lokalize kanser & 1.724 & 352 & 79,6 & $\mathbf{8 6 , 3}$ & $\mathbf{7 0 , 0}$ \\
Lokal ileri kanser & 487 & 148 & 69,6 & $\mathbf{7 8 , 1}$ & $\mathbf{6 2 , 7}$ \\
Metastatik dönem & 390 & 299 & 23,3 & $\mathbf{2 1 , 7}$ & $\mathbf{1 4 , 0}$ \\
\hline
\end{tabular}


Erişkin ve 19 yaş altı çocuklarda seminomnonseminom tip olmalarına göre testis tümörlerinin karşılaştırılmasında erişkinlerde; seminomların (\%48.8), çocuklarda \%7.1, non seminom tümörlerde ise; erişkinlerde \%51.2, çocuklarda \%92.9 olduğu görülmüştür. Bu istatistiksel olarak anlamlıdır $(p<0.0001)$ (Tablo-6, Şekil-5).

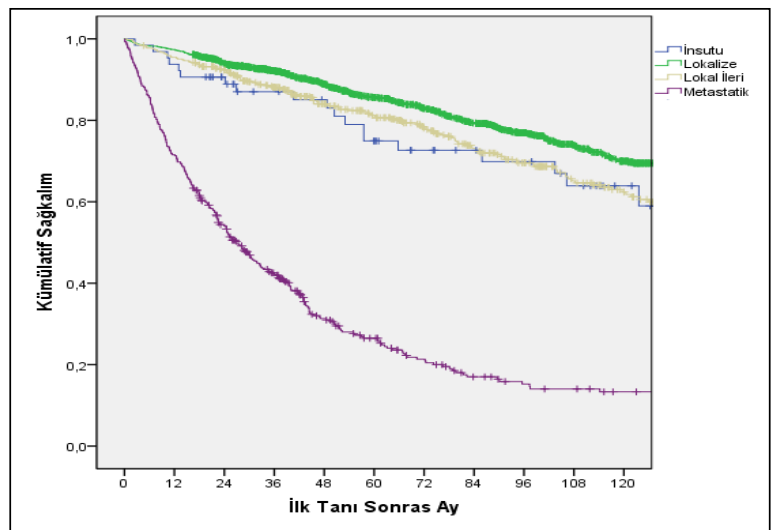

Şekil-4. Prostat kanserinde evrelere göre sağ kalım grafiği.

Tablo-6. Testis tümörlerinde seminom ve nonseminomların erişkin ve çocukluk çağına göre karşılaştırılması.

\begin{tabular}{lllllll}
\hline \multirow{2}{*}{ Histoloji } & \multicolumn{2}{l}{$\mathbf{0 - 1 9}$ Yaş } & \multicolumn{2}{c}{ 20+Yaş } & \multicolumn{2}{c}{ Toplam } \\
\cline { 2 - 7 } Seminom & $\mathbf{n}$ & $\%$ & $\mathbf{n}$ & $\%$ & $\mathbf{n}$ & $\%$ \\
\cline { 2 - 7 } & 5 & 7,1 & 386 & 48,8 & 391 & 45,4 \\
Non Seminom & 65 & 92,9 & 405 & 51,2 & 470 & 54,6 \\
Toplam & 70 & 100,0 & 791 & 100,0 & 861 & 100,0 \\
\hline
\end{tabular}

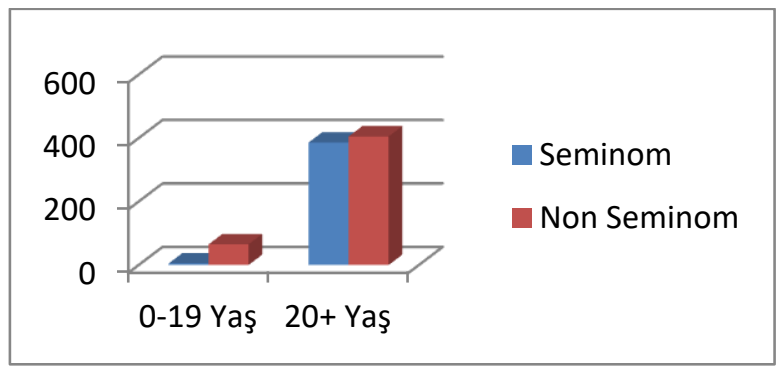

Şekil-5.Testis tümörlerinde seminom ve nonseminomların erişkin ve çocukluk çağına göre karşılaştırılması grafiği.

Evreleme yapılabilen tüm testis tümörü olgularında dağılım Şekil-6'de görülmektedir. Testis tümörlerinde beş ve 10 yıllık sağ kalımlar sırasıyla $\% 86,6$ ve \%82.9'dir. Histopatolojiye göre beş ve 10 yıllık GSK sırasıyla; seminomlarda $\% 95,7$ ve
$\% 94,2$, non seminomlarda ise $\% 80,6$ ve $\% 75,2$ 'ye düşmektedir (Wilcoxon (Gehan) Statistic=31.426 $p<0,001$ ) (Tablo-7, Şekil-7).

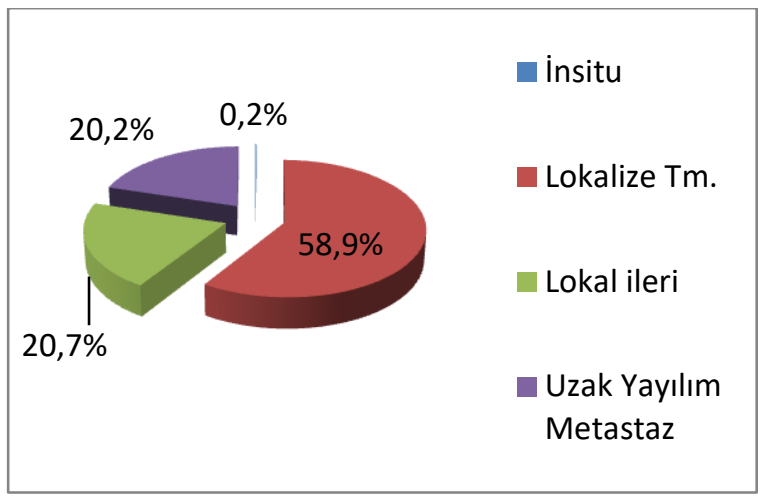

Şekil-6. Testis tümörlerinde evrelere göre dağılım.

Tablo-7. Testis tümörlerinde histopatolojiye göre sağ kalım.

\begin{tabular}{llllllll}
\hline & & \multicolumn{2}{c}{ Ölüm } & \multicolumn{2}{c}{ Yaşayan } & & \\
\cline { 3 - 6 } Histoloji & $\mathbf{n}$ & $\mathbf{n}$ & $\%$ & 1 Yıl & $\mathbf{5}$ yıl & $\mathbf{1 0}$ yıl \\
\hline $\begin{array}{l}\text { Seminom } \\
\begin{array}{l}\text { Non- } \\
\text { Seminom }\end{array}\end{array}$ & 249 & 20 & 92,0 & 99,1 & 95,7 & 94,2 \\
\hline
\end{tabular}

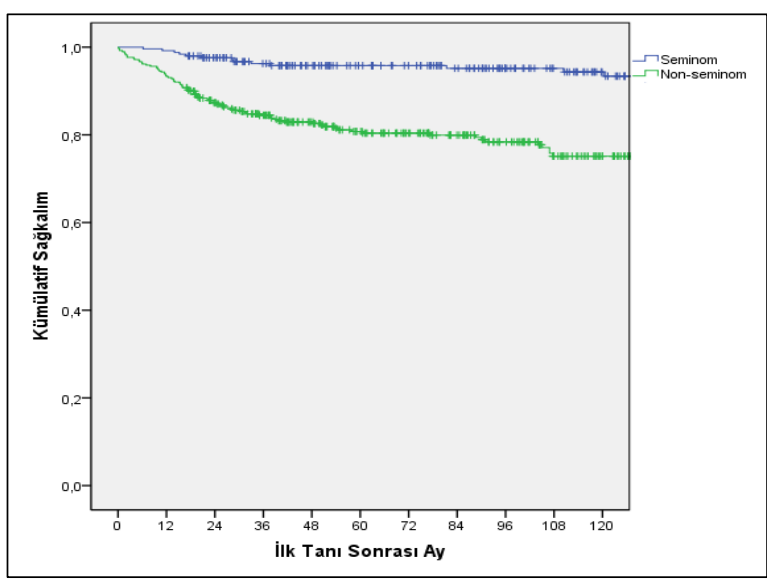

Şekil-7. Testis tümörlerinde histopatolojiye göre sağ kalım eğrileri.

\section{Tartışma}

GLOBOCAN 2018 verilerine göre tüm dünyada erkeklerde kanser insidansında sıklık açısından sıralamada prostat kanseri, akciğer kanserinden sonra ikinci sıklıkta izlenmektedir (2). Amerika Birleşik Devletleri'nde ise prostat kanseri birinci sırada görülmektedir (3). Keza 40 Avrupa ülkesinin kanser insidansı ve mortalitesi çalışmasında Avrupa'da erkeklerde en sık 
görülen kanser prostat kanseridir (4). Erkeklerde Kuzey ve Güney Amerika'daki tüm ülkeler, Avustralya ve Avrupa'nın çoğu ülkesinde prostat kanseri en sık görülen kanserdir. Türkiye kanser verilerinde ise erkeklerde genital sistem kanserleri solunum ve sindirim sistemi kanserlerinden sonra üçüncü sırada gelmektedir (5). Bizim serimize gelince, sistemlere göre görülüş sıklığımızda erkeklerde EGSK solunum, sindirim sistemi ve baş-boyun kanserlerinden sonra 4. sırada \%10,1 ile yer almaktadır.

Prostat kanseri tüm dünyada mortalite açısından akciğer, karaciğer, mide, kolorektal kanserler arkasından beşinci sırada yer almaktadır (2). Amerika Birleşik Devletleri'nde ise mortalitede akciğer kanserinin hemen ardından ikinci sıradayken (3), Avrupa çalışmasında akciğer ve kolorektal kanserlerin ardından üçüncü sırada bulunmuştur. Bizim olgularımızda ise mortalite açısından prostat kanseri akciğer, hemopoetik sistem ardından üçüncü sırada gelmektedir (4). Sistemlere göre 10 yıllık sağ kalımda erkek genital kanser olgularımız, baş-boyun, meme ve lenfatik sistem ardından \%59 oranı ile dördüncü sıradadır.
Literatürde testis tümörleri prostat kanserlerine göre daha erken yaşlarda görülmektedir. Bizim olgularımızda da bu durum dikkat çekicidir. Seminomlar 30-40 yaşlarında, non-seminomlar ise daha erken yaşlarda izlenmektedir (3). Bizim hastalarımızda da literatürle uyumlu olarak nonseminomlara biraz daha erken yaşta rastlanmıştır. Testis kanserlerinde mortalite oranları etkin kemoterapi rejimleri ve multidisipliner yaklaşımlar nedeniyle gittikçe azalmaktadır.

\section{Sonuç}

EÜH Kanser Kayıt sisteminde EGSK tüm sistemler arasında \%5,3 oranında yer almaktadır. EGSK'nin \%84,5'i prostat, \%15,3'ü testis kanseri, $\% 0,2$ 'lik küçük bir bölümü penis, skrotum ve diğer genital bölge kanserleridir. Yıllar içinde görülme sıklığı açısından prostat kanserinde doğrusal artış saptanmıştır. Prostat kanserinde beş ve 10 yıllık GSK oranları sırasıyla $\% 74,2$ ve $\% 55,2$, testis tümörlerinde ise $\% 86,6$ ve $\% 82,9$ bulunmuştur. Seminomlarda 10 yıllık sağ kalım $\% 94,2$ iken non-seminomlarda \%75,2'ye düşmektedir.

\section{Kaynaklar}

1. Jemal A, Vineis P, Bray F, Torre L, Forman D (Editörler). Kanser Atlası. İkinci Baskı. Atlanta, GA: Amerikan Kanser Derneği; 2014. www.cancer.org/canceratlas

2. Bray F, Ferlay J, Soerjomataram I et al. Global Cancer Statistics 2018: GLOBOCAN Estimates of Incidence and Mortality Worldwide for 36 Cancers in 185 Countries. Cancer J Clin. 2018;68:394-424.

3. Siegel RL, Miller KD, Jemal ACA. Cancer Statistics, 2018. CA CANCER J CLIN 2018;68:7-30.

4. Ferlay J, Colombet M, Soerjomataram I et al. Cancer incidence and mortality patterns in Europe: Estimates for 40 countries and 25 major cancers in 2018. European Journal of Cancer 103 (2018) 356-87.

5. Gültekin M, Boztaş G. Türkiye Kanser İstatistikleri. TC Sağlık Bakanlığı, Türkiye Halk Sağlığı Kurumu, Kanser Savaş Daire Başkanlığı. 2016. 